\title{
Deep water observations of extreme waves with moored and free GPS buoys
}

\author{
Takuji Waseda $\cdot$ Masato Sinchi $\cdot$ Keiji Kiyomatsu • \\ Tomoya Nishida $\cdot$ Shunsuke Takahashi $\cdot$ Sho Asaumi • \\ Yoshimi Kawai • Hitoshi Tamura • Yasumasa Miyazawa
}

Received: 26 January 2014 / Accepted: 9 July 2014 / Published online: 27 July 2014

(C) The Author(s) 2014. This article is published with open access at Springerlink.com

\begin{abstract}
Point-positioning GPS-based wave measurements were conducted by deep ocean (over 5,000 m) surface buoys moored in the North West Pacific Ocean in 2009, 2012, and 2013. The observed surface elevation bears statistical characteristics of Gaussian, spectrally narrow ocean waves. The tail of the averaged spectrum follows the frequency to the power of -4 slope, and the significant wave height and period satisfies the Toba's $3 / 2$ law. The observations compare well with a numerical wave hindcast. Two large freak waves exceeding $13 \mathrm{~m}$ in height were observed in October 2009 and three extreme waves around $20 \mathrm{~m}$ in height were observed in October 2012 and in January 2013. These extreme events are associated with passages of a typhoon and a mid-latitude cyclone. Horizontal movement of the buoy revealed that the orbital motion of the waves at the peak of the wave group mostly exceed the weakly nonlinear estimate. For some cases, the orbital velocity exceeded the group velocity, which might indicate a breaking event but is not conclusive yet.
\end{abstract}

Responsible Editor: Val Swail

This article is part of the Topical Collection on the 13th

International Workshop on Wave Hindcasting and Forecasting in Banff, Alberta, Canada October 27 - November 1, 2013

T. Waseda $(\bowtie) \cdot$ M. Sinchi $\cdot$ K. Kiyomatsu $\cdot$ T. Nishida $\cdot$

S. Takahashi $\cdot$ S. Asaumi

Department of Ocean Technology Policy and Environment, Graduate

School of Frontier Science, The University of Tokyo, 5-1-5,

Kashiwano-ha, Kashiwa, Chiba, Japan 277-8563

e-mail: waseda@k.u-tokyo.ac.jp

T. Waseda $\cdot$ H. Tamura $\cdot$ Y. Miyazawa

Application Laboratory, Japan Agency for Marine-Earth Science and Technology, 3137-25, Showa-machi, Kanazawa-ku, Yokohama, Japan 236-0001

Y. Kawai

Research and Development Center for Global Change, Japan Agency for Marine-Earth Science and Technology, 2-15 Natsushima-Cho, Yokosuka, Japan 237-0061
Keywords GPS wave sensor · Deep ocean slack-moored buoy $\cdot$ Wave hindcast $\cdot$ Extreme waves $\cdot$ Nonlinear wave . Wave group

\section{Introduction}

Observing waves in the open ocean is still a challenge. The only instrument that can map the significant wave height globally is the satellite altimeter. However, altimeters cannot detect wave direction and the observation interval is rather long. Satellite synthetic aperture radar (SAR) can provide an estimate of the directional spectrum, but it is not practical to use SAR to monitor waves regularly. For these reasons, waves are mapped globally based on numerical wave model. Therefore, altimeter and wave forecast/hindcast data ought to be validated by moored wave riders or bottom mounted wave sensors located mostly in relatively shallow waters (e.g., NDBC buoys, Swail et al. 2010, Nowphas system in Japan, Nagai et al. 2005). There are, however, a number of meteorological and tsunami monitoring buoys in deep waters such as TAO array and DART buoys. Conceivably, these buoys can be used to measure waves by monitoring the motion of the platform assuming that the buoy follows the surface. A point-positioning GPS sensor was attached to the meteorological buoy (K-TRITON) of Japan Agency for Marine-Earth Science and Technology in the North-West Pacific in 2009 and in 2012 (Waseda et al. 2011a). The advantage of the GPS wave sensor over conventional accelerometer is the ease of the analysis. The accelerometer data can be contaminated by low-frequency noise and the high-pass filter applied to remove the noise can artificially enhance the extreme wave height (Collins et al. 2014).

Extreme waves or the freak waves have been studied extensively in the past few decades. Freak waves are statistically rare waves defined as waves exceeding twice or 2.2 times the significant wave height. Extreme waves, on the other 
hand, may refer to freak waves, freak and giant waves, giant but not freak waves, and possibly unexpected waves. In this paper, we use the term extreme waves referring to large waves but not necessarily exceeding twice the significant wave height. The key to understanding extreme wave generation mechanism is reliable observational evidence. One of the most well studied freak wave is the Draupner Wave observed in January 11995 (Haver 2004). However, the wave was measured remotely by down-looking laser which might be subject to uncertainty (Magnusson et al. 2013). Gigantic waves observed in Taiwan during passage of typhoon Krosa (Liu et al. 2008) was measured by an accelerometer which might produce anomalously large wave height if not properly processed (Collins et al. 2014). Therefore, a direct measurement of extreme wave by GPS sensor might become an attractive alternative for observing extreme waves offshore. The accuracy of the measurement depends on how well the platform follows the wave motion. Tulin and Landrini (2001) documented the kinematic properties of breaking wave and showed that when the particle velocity exceeds the group velocity the waves will inevitably undergo breaking. The implication is that even the orbital velocity of non-breaking wave can reach the group velocity without undergoing severe breaking event. Extreme waves are not necessarily a breaking wave, but the horizontal motion of the particle can accelerate to reach the group velocity or it might even exceed the group velocity. To understand the ability of a tethered wave to detect extreme waves, its horizontal motion will be studied.

The principle of the GPS wave measurement and dynamic analysis of buoy motion will be outlined in Section 2. The mean wave statistics from the 2009 and 2012-2013 observations will be compared with wave model estimates in Section 3. During the total of about 12 months of observation, two freak waves around $12 \mathrm{~m}$ in height and three giant waves of around $20 \mathrm{~m}$ in height were observed. The horizontal motion of the buoy will be analyzed including these giant waves in Section 4. The kinematic properties of the nonlinear waves inferred from the observations will be discussed in the context of wave tank experiment in Section 5. Conclusions follow.

\section{Principle of GPS-based wave observations in the deep ocean}

The first open-ocean buoy measurement was conducted from August 30 to December 6, 2009 utilizing the JAMSTEC KTRITON buoy at the JKEO site (JAMSTEC Kuroshio Extension Observatory, $38^{\circ} 05^{\prime} \mathrm{N}, 146^{\circ} 25^{\prime} \mathrm{E}$, and $5,400 \mathrm{~m}$ deep, phase 4, Fig. 1). The K-TRITON is a slack-moored buoy system whose mooring cable length is approximately $7,700 \mathrm{~m}$ long, the lower $2,500 \mathrm{~m}$ is buoyant, and the $700 \mathrm{~m}$ wire cable at the top and 4,500-m Nylon rope in the middle are sinkable (Fig. 2). In stagnant water, the cable is designed to form an $\mathrm{S}$ shape, but when there is a current field, the mooring cable can straighten completely and elongate. The second successful open-ocean observation was conducted at the New Kuroshio Extension Observatory (NKEO, 144.8E 33.8 N, Fig. 1) from June 20, 2012 to March 23, 2013. The particulars of the K-TRITON buoy and the mooring cables were nearly identical for the JKEO and NKEO systems ${ }^{1}$.

The GPS longitude, latitude and altitude were recorded at $2.5 \mathrm{~Hz}$ for $20 \mathrm{~min}$ on the hour. The raw time series are recorded on storage and when an event occurs (e.g., significant wave height over $3 \mathrm{~m}$ ), are transmitted by Iridium communication. The derived data that are processed on board are transmitted using Iridium satellite telemetry every hour. Thus the buoy motion during the observation period can be monitored by the GPS locations. When the NKEO mooring cable got cut loose in March 2013, the buoy started to drift away, and within 2 weeks, it was about $400 \mathrm{~km}$ apart from the original location (Fig. 1). During this time, the buoy was freely floating without a constraint of the mooring cable.

The open-ocean observation at JKEO and a reference measurement at stationary point on land (Table 1) with the same GPS sensor were analyzed to determine coefficients of filters to remove GPS noise and effect of unwanted pitch/roll resonance. Unlike the commonly used Real Time Kinematic (RTK) GPS wave sensor, the point-positioning GPS wave sensor does not require a reference station. Although infamous for large errors, it is known that the noise of the pointpositioning GPS sensor is mostly confined to low frequencies. Taking advantage of the spectral characteristics of the GPS noise, Yamaguchi et al. (2005) proposed to use a high-pass filter to decipher the wave signal from GPS noise. A number of point-positioning GPS wave buoys were developed recently for the use in the open ocean (see Waseda et al. 2011a). A typical GPS noise spectrum from a stationary platform is shown in Fig. 3. The GPS noise level (red line) drops off at roughly $f^{-2}$, and at the frequency range of typical ocean waves, the noise level is $30 \mathrm{~dB}$ lower than the wave energy. Thus, a simple high-pass filter with a 30 -s cutoff period would work to decipher the wave signal from point-positioning GPS record.

The quality of the GPS wave observation depends on the Response Amplitude Operators (RAOs) or the transfer functions of the buoy. Because of lack of data and difficulty in including the effect of cable constraint, the RAOs were numerically estimated by empirically determining the unknown buoy parameter (see Appendix 1 for detail). The natural frequency of the estimated heave motion was around $0.55 \mathrm{~Hz}$ but the effect was hardly detectable in the observed heave spectrum (indicated by black arrow in Fig. 3). On the other hand, a noticeable peak around $0.36 \mathrm{~Hz}$ appears in the

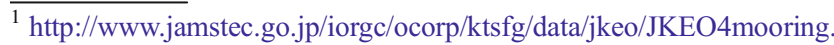
$\mathrm{htm}$
} 
Fig. 1 Locations of the JKEO (Jamstec Kuroshio Extension Observatory) and NKEO (New Kuroshio Extension Observatory) observation sites, and the Hiratsuka observation tower. A line originating from the NKEO buoy indicates the trajectory of the buoy which drifted from March 8 to 23, 2013

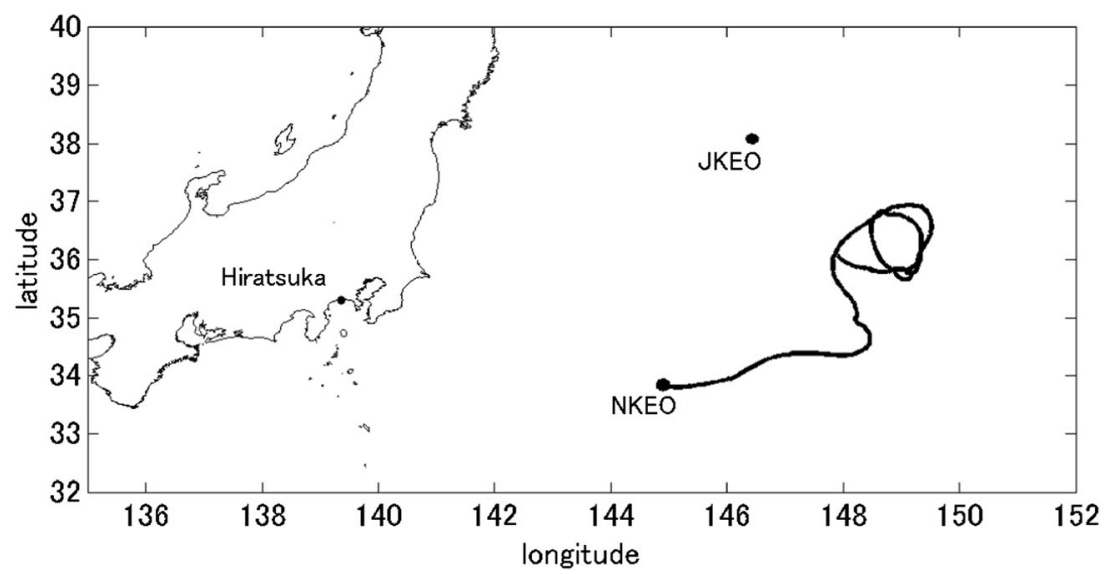

spectrum of the horizontal motion (east-west or north-south), indicated by black arrow in Fig. 3, right. It turns out that the anomalous peak appears as a result of pitch or roll resonance but not because of the surge or sway resonance. The natural frequency of the roll/pitch motion of the buoy explains well the observed anomalous peak in the spectrum (Appendix 1).

Based on these analyses, the filter coefficients were determined: the cutoff frequency of the high-pass filter for the heave motion is set to $0.03 \mathrm{~Hz}$; the cutoff frequencies of the band-pass filter for the pitch/roll motion are set to 0.045 and $0.28 \mathrm{~Hz}$. With these filters, the bias of the stationary record reduced to about $0.01 \mathrm{~m}$ and the root-mean-square error to be $0.02 \mathrm{~m}$, thus, successfully removing the low frequency GPS noise error. The analysis conducted in this study did not apply the RAO corrections (Sinchi 2011). The impact of RAOs was

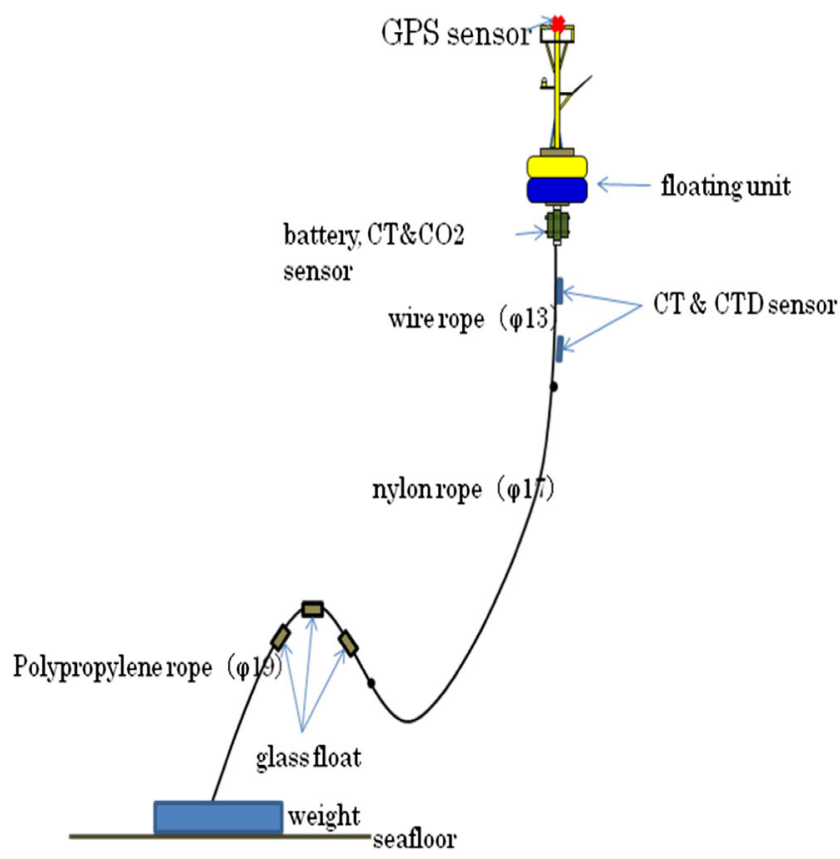

Fig. 2 K-TRITON Buoy slack-mooring configuration. The top part (wire and nylon ropes) is sinkable and the bottom part up to the glass float (Polypropylene rope) is buoyant mostly negligible for our observation (Appendix 1). In the range of 0.05 to $0.2 \mathrm{~Hz}$, the heave amplitude response was nearly 1 and phase shift was negligible $\left(5^{\circ}\right.$ at $\left.0.47 \mathrm{~Hz}\right)$. On the other hand, the surge response amplitude gradually decreases to around 0.93 at $0.2 \mathrm{~Hz}$.

For the analysis of horizontal velocity (Section 4), further quality control was made based on the estimated KeuleganCarpenter number (KC number hereafter). Based on the estimated horizontal velocity of the buoy $U$ for the given wave, the $\mathrm{KC}$ number is estimated as $\mathrm{KC}=U T / D$ where $T$ is the corresponding zero-up/down-crossing wave period and $D$ is the diameter of the K-TRITON buoy $(2.1 \mathrm{~m})$. The threshold was set to $\mathrm{KC}=40$ which limits the analysis of the horizontal motion of the buoy to waves of length $200 \mathrm{~m}$ in average (Table 1). Therefore, the horizontal excursion of the buoy is assured to be sufficiently large compared to the buoy itself.

The observed wave heights were calibrated in two steps. First, a small drifting type GPS buoy was moored near an observation tower at Hiratsuka (see Fig. 1 for location) and the observed wave heights $H_{1 / 10}$ were compared to the ultra-sonic wave sensor data attached to the tower (Fig. 4, left). Then, the observed significant wave height, $H_{1 / 3}$, from the K-TRITON buoy was compared against $H_{1 / 3}$ from the GPS drifting buoy deployed simultaneously at the JKEO site. They compared well until the drifting buoy was over $100 \mathrm{~km}$ away (Fig. 4, right, Waseda et al. 2011a). Therefore, the altitude observed by K-TRITON buoy seems to represent well the surface elevation. In the next section, we further validate the observed wave statistics.

\section{Observed wave statistics and comparison with wave model}

To assure that the buoy had indeed followed the path of a water particle at the surface, basic wave parameters were estimated from the buoy position record of the JKEO. First, the statistics of the elevation were estimated (Fig. 5, upper 
Table 1 Summary of observed wave parameters

\begin{tabular}{|c|c|c|c|c|c|c|}
\hline Observation & \multicolumn{2}{|l|}{ JKEO } & \multicolumn{2}{|l|}{ NKEO } & \multicolumn{2}{|c|}{ NKEO/drift } \\
\hline Period & \multicolumn{2}{|c|}{ August 30, 2009-December 6, 2009} & \multicolumn{2}{|c|}{ June 20, 2012-March 8, 2013} & \multicolumn{2}{|c|}{ March 8-23, 2013} \\
\hline Number of records & \multicolumn{2}{|c|}{$366^{\mathrm{a}}$} & \multicolumn{2}{|c|}{5,913} & \multicolumn{2}{|c|}{347} \\
\hline \multirow[t]{2}{*}{ Remarks (sections where analyzed) } & \multicolumn{2}{|c|}{ Section 2, 3, 4} & \multicolumn{2}{|c|}{ Section 3,4} & \multicolumn{2}{|c|}{ Section 3,4} \\
\hline & Zero-up & Zero-down & Zero-up & Zero-down & Zero-up & Zero-down \\
\hline Number of freak waves & 31 & 22 & 199 & 203 & 6 & 6 \\
\hline$\overline{H_{1 / 3}}$ & $3.8 \mathrm{~m}$ & $3.8 \mathrm{~m}$ & $2.7 \mathrm{~m}$ & $2.7 \mathrm{~m}$ & $3.3 \mathrm{~m}$ & $3.3 \mathrm{~m}$ \\
\hline$\overline{T_{1 / 3}}$ & $10.2 \mathrm{~s}$ & $10.2 \mathrm{~s}$ & $9.4 \mathrm{~s}$ & $9.4 \mathrm{~s}$ & $9.7 \mathrm{~s}$ & $9.7 \mathrm{~s}$ \\
\hline$\overline{a k_{1 / 3}}$ & 0.067 & 0.067 & 0.056 & 0.056 & 0.061 & 0.061 \\
\hline $\max H_{1 / 3}$ & $8.4 \mathrm{~m}$ & $8.3 \mathrm{~m}$ & $13.3 \mathrm{~m}$ & $13.4 \mathrm{~m}$ & $8.1 \mathrm{~m}$ & $8.3 \mathrm{~m}$ \\
\hline $\max H$ & $14.3 \mathrm{~m}$ & $13.2 \mathrm{~m}$ & $19.0 \mathrm{~m}$ & $22.8 \mathrm{~m}$ & $15.0 \mathrm{~m}$ & $14.0 \mathrm{~m}$ \\
\hline Number of records w. extreme waves of $K C>40$ & 64 & 70 & 445 & 472 & 28 & 26 \\
\hline$\overline{H_{1 / 3}}$ & $5.1 \mathrm{~m}$ & $4.9 \mathrm{~m}$ & $4.9 \mathrm{~m}$ & $4.9 \mathrm{~m}$ & $5.3 \mathrm{~m}$ & $5.6 \mathrm{~m}$ \\
\hline$\overline{T_{1 / 3}}$ & $10.9 \mathrm{~s}$ & $10.9 \mathrm{~s}$ & $10.6 \mathrm{~s}$ & $10.7 \mathrm{~s}$ & $10.9 \mathrm{~s}$ & $11.1 \mathrm{~s}$ \\
\hline$\overline{\mathrm{ak}_{1 / 3}}$ & 0.077 & 0.075 & 0.079 & 0.078 & 0.080 & 0.082 \\
\hline$\overline{H_{\text {ext. }}}$ & $8.4 \mathrm{~m}$ & $8.2 \mathrm{~m}$ & $8.2 \mathrm{~m}$ & $8.1 \mathrm{~m}$ & $8.9 \mathrm{~m}$ & $9.3 \mathrm{~m}$ \\
\hline$\overline{T_{\text {ext. }}}$ & $11.2 \mathrm{~s}$ & $11.2 \mathrm{~s}$ & $10.8 \mathrm{~s}$ & $10.9 \mathrm{~s}$ & $10.2 \mathrm{~s}$ & $10.6 \mathrm{~s}$ \\
\hline$\overline{\mathrm{ak}_{\mathrm{ext}}}$ & 0.145 & 0.141 & 0.153 & 0.148 & 0.175 & 0.168 \\
\hline$\overline{\left(U / c_{p} / \mathrm{ak}\right)_{\mathrm{ext}}}$ & 1.76 & 1.74 & 1.81 & 1.78 & 1.61 & 1.52 \\
\hline
\end{tabular}

${ }^{a}$ The wave sensor failed in December 2009 and stopped transmitting the data but spontaneously recovered from March to September 2010. The statistical analysis presented in Section 2 includes 32 additional data obtained in 2010.

left); the probability density function (pdf) is nearly Gaussian, and the pdf of the extremum is well approximated by the analytical formula of Cartwright and Longuet-Higgins (1956), Fig. 5, upper right. Thus, the observed surface elevation displays the characteristics of a random signal with narrow spectral bandwidth. The Fourier spectrum $S(f)$ from the elevation (or the buoy altitude) records were ensemble averaged (796 degrees of freedom). The saturation spectrum $B(f)=S(f) f^{4}$ in the range of 0.1 to $0.3 \mathrm{~Hz}$ (or 3 to 10 -s wave period) is nearly constant corresponding to the $f^{-4}$ equilibrium spectral tail (e.g., Toba 1973), Fig. 5, lower left. ${ }^{2}$ Consequently, the relationship between the non-dimensional significant wave height and the wave age agrees quite well with the Toba's $3 / 2$ law with a slight difference in the value of the constant $B$ (Fig. 5, lower right). From these comparisons, we can conclude that the free surface elevation is accurately traced by the moored K-TRITON buoy.

Next, the observed significant wave height will be validated against a wave hindcast. The time records of the significant wave height $\left(H_{1 / 3}\right)$ from the 2009 JKEO and 2012-2013 NKEO observations are plotted together with hindcasted $H_{m 0}$ in Fig. 6. JKEO $H_{1 / 3}$ is compared against the hindcast significant wave height $H_{m 0}$ of an original model and $H_{m 0}$ of

\footnotetext{
$\overline{2}$ The slight reduction of $\mathrm{B}(f)$ at $0.35 \mathrm{~Hz}$ and increase at $0.45 \mathrm{~Hz}$ do not correspond to heave or pitch/roll resonance frequencies and are overly emphasized compared to the spectral shape shown in Fig. 3. The drop off beyond $0.5 \mathrm{~Hz}$ cannot be explained by the heave RAO. Thus, these characteristics most likely represent the true wave signal.
}

the JMA operational Coastal Wave Model (Japan Meteorological Agency/CWM, e.g., Tauchi et al. 2007). The developed hindcast model (2007-2013) based on NOAA WaveWatchIII embeds the $0.1^{\circ} \times 0.1^{\circ}\left(124.9-148.1^{\circ} \mathrm{E}\right.$, 27.9-44. $\left.1^{\circ} \mathrm{N}\right)$ Japan model within the $1^{\circ} \times 1^{\circ}$ Pacific model $\left(100-290^{\circ} \mathrm{E},-65\right.$ to $\left.65^{\circ} \mathrm{N}\right)$; the wave direction is discretized at $10^{\circ}$ interval and the frequency is discretized for 35 frequencies at variable intervals between 0.0412 and $1.0521 \mathrm{~Hz}$. First, the reanalysis and analysis wind products (ERA-interim, NCEP-CFSR, NCEP-GFS and JMA-GSM ${ }^{3}$ ) were validated against observed wind records (NDBC buoys, TAO-TRITON buoys, Nowphas buoys and JKEO buoys ${ }^{4}$ ), and then the Pacific wave model outputs forced by these winds were validated against the observed wave records (NDBC buoys, Nowphas buoys and JKEO buoy); the bias tended to be

\footnotetext{
${ }^{3}$ ERA-interim: European ReAnalysis-interim (Dee et al. 2011) NCEP-CFSR: NCEP-Climate Forecast System Reanalysis (Saha et al. 2010)

NCEP-GFS: National Centers for Environmental Prediction - Global Forecast System (NCEP Office Note 442 2003)

JMA-GSM: Japan Meteorological Agency-Global (Mizuta et al. 2006)

${ }^{4}$ NDBC: National Data Buoy Center (Meindl and Hamilton 1992)

TAO: Tropical Atmosphere Ocean (McPhaden et al. 2010)

TRITON: Triangle Trans-Ocean Buoy Network (Kuroda and Amitani 2001)

Nowphas: Nationwide Ocean Wave information network for Ports and HArbourS (Nagai et al. 2005)

JKEO: Japan Kuroshio Extention Observatory (Tomita et al. 2010)
} 


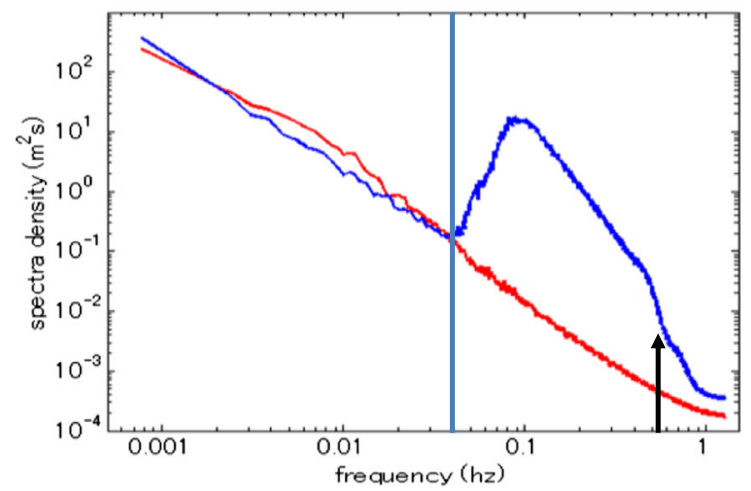

Fig. 3 The noise spectrum of the point-positioning GPS heave signal (red line) and the averaged spectrum derived from the JKEO (JAMSTEC Kuroshio Extension Observatory) observation (blue line). Left figure is heave motion and right figure is East-west motion. The vertical blue lines are the cutoff frequency for the removal of GPS noise and roll resonance.

smallest with ERA-interim wind but the correlation was highest with JMA-GSM wind near Japan. Eventually, JMAGSM was chosen to force the Pacific model and JMA-MSM was chosen to force the Japan model (Waseda et al. 2014). The hindcasted wave height compares well with the observations (Fig. 6), except at extreme events when the model tends to underestimate the $H_{\mathrm{s}}$. The JKEO observation was compared against CWM estimates as well. The resolution of CWM is $0.05^{\circ}$ around Japan $\left(120-150^{\circ} \mathrm{E}, 20-50^{\circ} \mathrm{N}\right)$ and 72 -h wave forecast was available. The time series of the significant wave heights among wave products compares reasonably well. The standard deviation (around $1 \mathrm{~m}$ ), the centered root-meansquare differences and the correlation (around 0.95) are depicted in the Taylor diagram (Fig. 7). The centered rootmean-square difference is larger and the correlation is lower between CWM and the observation (point $\mathrm{C}$ in Fig. 7, left) than our simulation and the observation (point B in Fig. 7, left). The model was validated against NKEO observation as

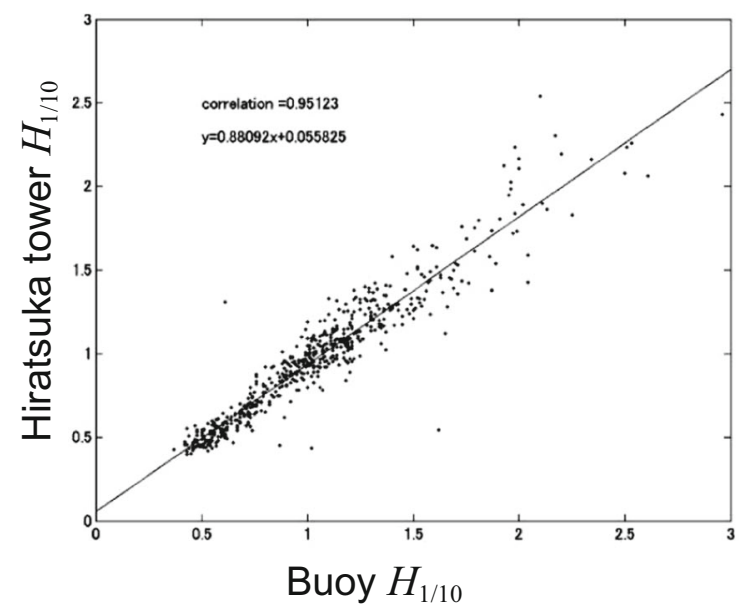

Fig. 4 (Left) Scatter diagram of the 1/10 significant wave heights of the drifting GPS wave buoy compared with tower measurements (correlation 0.95). (Right) Scatter diagram of the $1 / 3$ significant wave heights of the

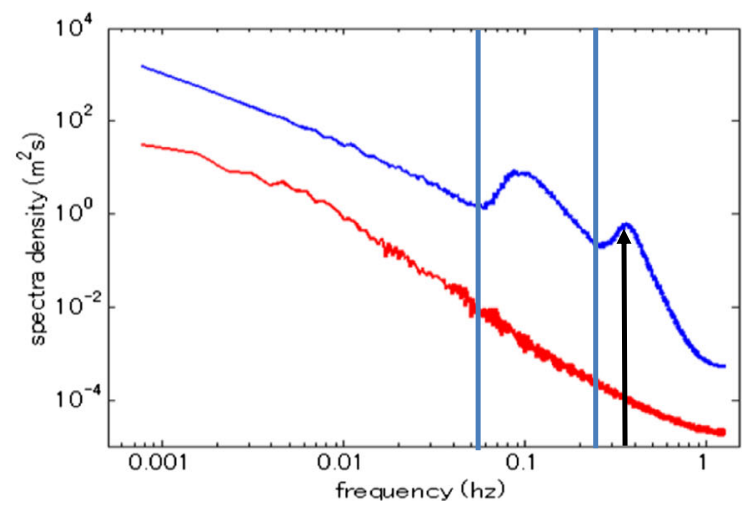

The cutoff frequency of the high-pass filter for the heave motion is $0.03 \mathrm{~Hz}$ and those of the band-pass filter for the east-west motion are 0.045 and $0.28 \mathrm{~Hz}$. The arrows indicate the numerically estimated resonance frequency of heave and pitch/roll

well (Fig. 7, right). The correlation is slightly smaller (0.90) than JKEO, and both the standard deviation (around $1.2 \mathrm{~m}$ ) and centered rms difference are slightly larger than JKEO case, because of seasonal variation. Overall, we conclude that both the JKEO and NKEO wave observations compare reasonably well with the Hindcast simulations.

\section{Buoy trajectories and inferred orbital motions of extreme waves in a wave group}

Moored at a depth of about $5,700 \mathrm{~m}$, the K-TRITON buoy at NKEO has moved as much as $7,000 \mathrm{~m}$ or equivalently $0.07^{\circ}$ in latitude from the sinker location (Fig. 8, left). The colored dots in Fig. 8 are 20-min-long trajectories of the buoy position; the color represents maximum wave height of each record. The buoy position is not always on the circumference of the circle and is moving around within the circle. Similar buoy motion

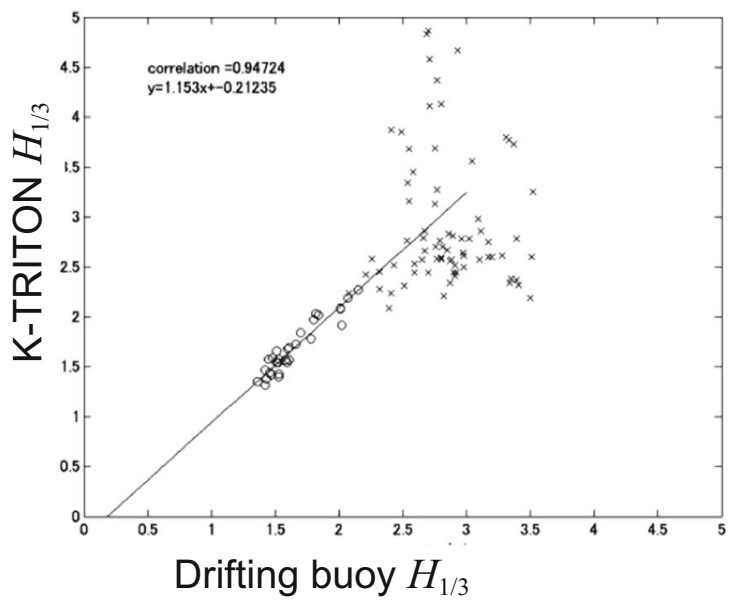

drifting GPS wave buoy and the K-TRITON buoy (correlation 0.95 when buoys are less than $100 \mathrm{~km}$ apart). The circles represent observations of waves when the distance between the buoys was less than $100 \mathrm{~km}$ 
Fig. 5 The probability density function (pdf) of the surface elevation (upper left) and of the extreme value of the surface elevation (upper right). The Gaussian pdf and the Cartwright and Longuet-Higgins theoretical estimate for the extreme value pdf are shown together in red line. Saturated spectrum $B(f)=S(f) f^{4}$ estimated from all the records is shown in lower left diagram (396 degrees of freedom). Frequency (in hertz) is shown on the horizontal axis and saturation on the vertical axis. The nondimensional significant wave height is plotted against wave age in lower right diagram. The solid line is a fit corresponding to Toba's $3 / 2$ law
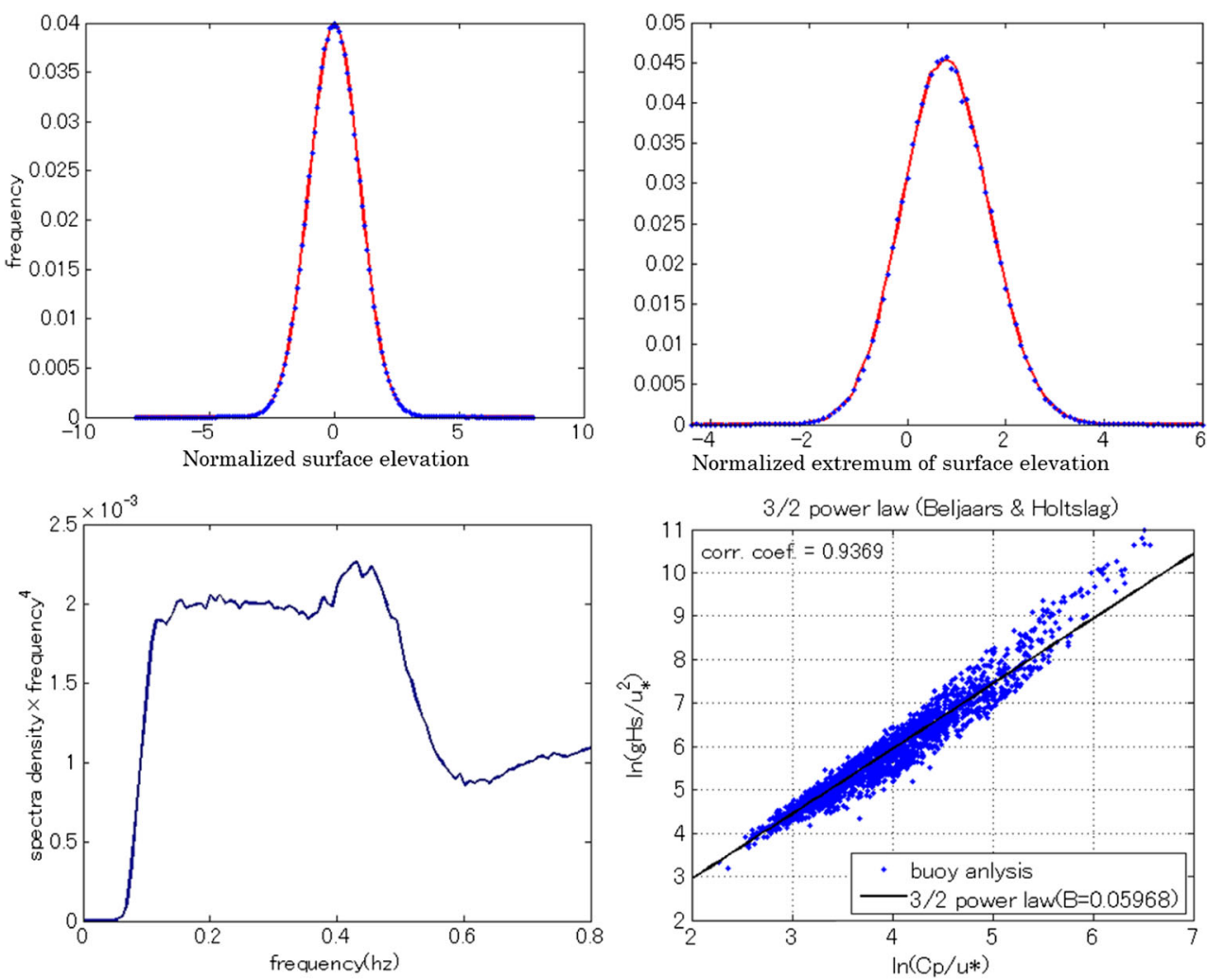

was observed at the JKEO K-TRITON buoy as well. During the observations in 2009 and in 2012-2013, a few notable extreme waves were observed. In October 26, 2009, 19:00 (UTC) and in October 27, 2009, 16:00 (UTC) during passage of typhoon 20, freak waves exceeding $10 \mathrm{~m}$ were observed; $12.3 \mathrm{~m}$ wave height $\left(H_{1 / 3}=5.8 \mathrm{~m}\right)$ and $13.2 \mathrm{~m}$ wave height $\left(H_{1 / 3}=6.6\right)$, respectively. These two freak waves have distinct directional characteristics, former being narrow and latter being broad (e.g., Waseda et al. 2011b). On October 4, 2012, extreme waves of $22.8-\mathrm{m}$ wave height $\left(H_{1 / 3}=13.4\right)$, and $17.3-\mathrm{m}$ wave height $\left(H_{1 / 3}=10.3\right)$ were observed during passage of typhoon 19. And on January 14, 2013, an extreme wave height $17.7 \mathrm{~m}\left(H_{1 / 3}=10.0\right)$ was observed during passage of a bomb cyclone. These waves were not freak waves. The
Fig. 6 Time series of significant wave height compared against wave hindcast estimates. (top) The JKEO observation $H_{1 / 3}$ (dots) with original WaveWatchIII hindcast $H_{m 0}$ (solid line) and JMA/CWM hindcast $H_{m 0}$ (dashdotted line). (Bottom) The NKEO observation $H_{1 / 3}$ (dots) with original WaveWatchIII hindcast $H_{m 0}$ (solid line)
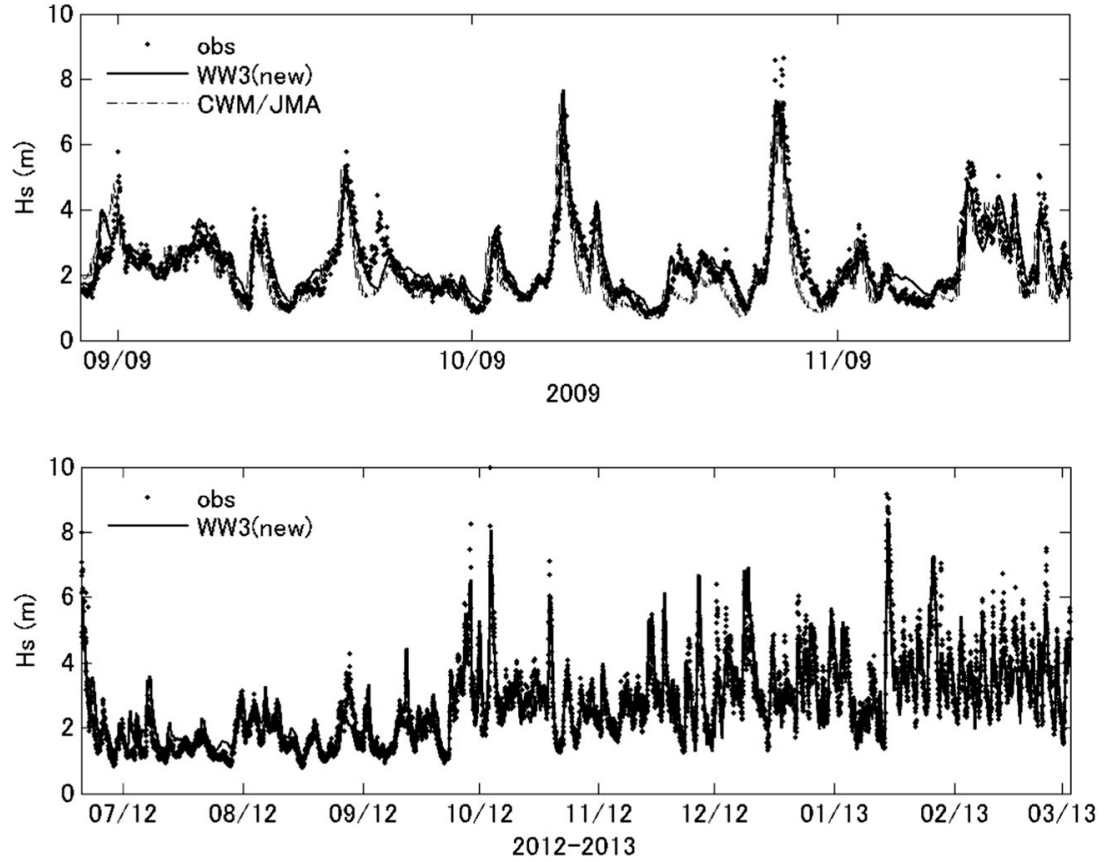


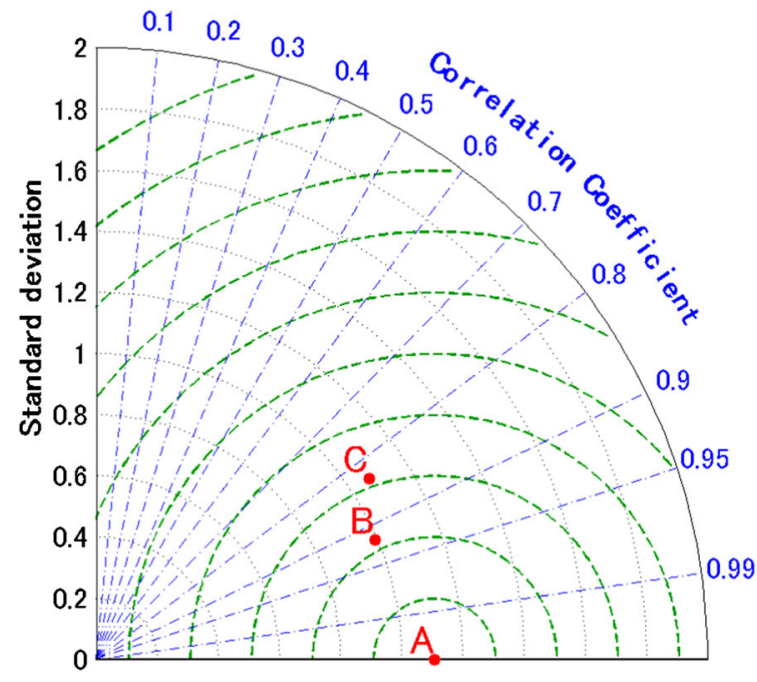

Fig. 7 Taylor diagram comparing the significant wave height $\left(H_{\mathrm{s}}\right)$ from the observation $(A)$ and wave hindcasts. In the left diagram, JKEO observed $H_{1 / 3}$ is compared against WaveWatchIII hindcast $H_{m 0}(B)$, and

buoy trajectory of the largest waves observed by the KTRITON buoy $(22.8 \mathrm{~m}$ on October 4,2012$)$ will be studied in more detail.

The buoy trajectory from the 20-min record at 01:00 October 4, 2012 (UTC), shows an almost linear translation $(\sim 18 \mathrm{~cm} / \mathrm{s})$ and a random motion due to wave (Fig. 9, left). In the middle of the record, corresponding to the largest wave, the buoy makes a leap in its horizontal position. Comparing the time series of elevation, zonal position and meridional position, it is apparent that the buoy position shifted largely at the front-face of the wave (Fig. 9, right column). Between the zero-up-crossing point (circle) and the zero-down-crossing point (down-pointing triangle) in the surface elevation time series, the horizontal position changes about $36 \mathrm{~m}(10 \mathrm{~m}$ zonally and $34 \mathrm{~m}$ meridionally), which corresponds to $11.5 \mathrm{~m} / \mathrm{s}$ horizontal speed of the buoy. Since the corresponding phase speed and wave period are $23.7 \mathrm{~m} / \mathrm{s}$ and $15 \mathrm{~s}$,

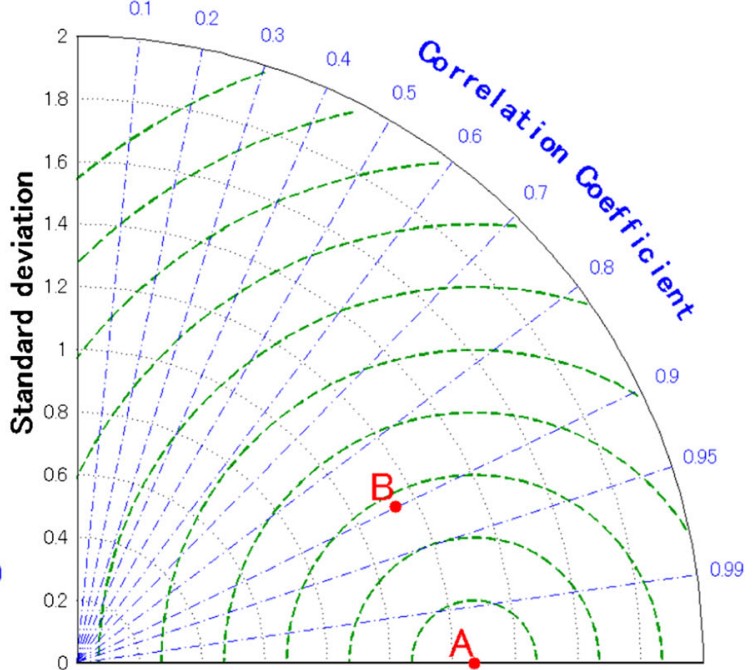

JMA/CWM hindcast $(C)$. In the right diagram, NKEO observed $H_{1 / 3}$ is compared against the WaveWatchIII hindcast $H_{m 0}(B)$

respectively, the ratio of the maximum horizontal motion and the phase speed is 0.48 . This means that the horizontal speed of the water particle reached group velocity. On the other hand, for the $17.3 \mathrm{~m}$ maximum wave height $\left(H_{1 / 3}=10.3\right)$ case which was observed just an hour later (01:00 October 4, 2012 [UTC]), the maximum horizontal speed was much smaller $(4.8 \mathrm{~m} / \mathrm{s})$, Fig. 10. Nevertheless, because the steepness, ak, of the corresponding wave is around 0.17 , the estimated horizontal speed exceeds that of the weakly non-linear wave $U=(\mathrm{ak}) C_{p}$ where ak $=0.2$.

For a narrow banded wave system, a wave group is formed and the waves break when the individual wave passes through the peak of the envelope (Donelan et al. 1972). As the wave undergoes breaking, the horizontal velocity of the fluid particle accelerates and exceeds the phase speed. It is known that even for a non-breaking wave, a wave group is formed, and the velocity of the water particle exceeds the weakly non-
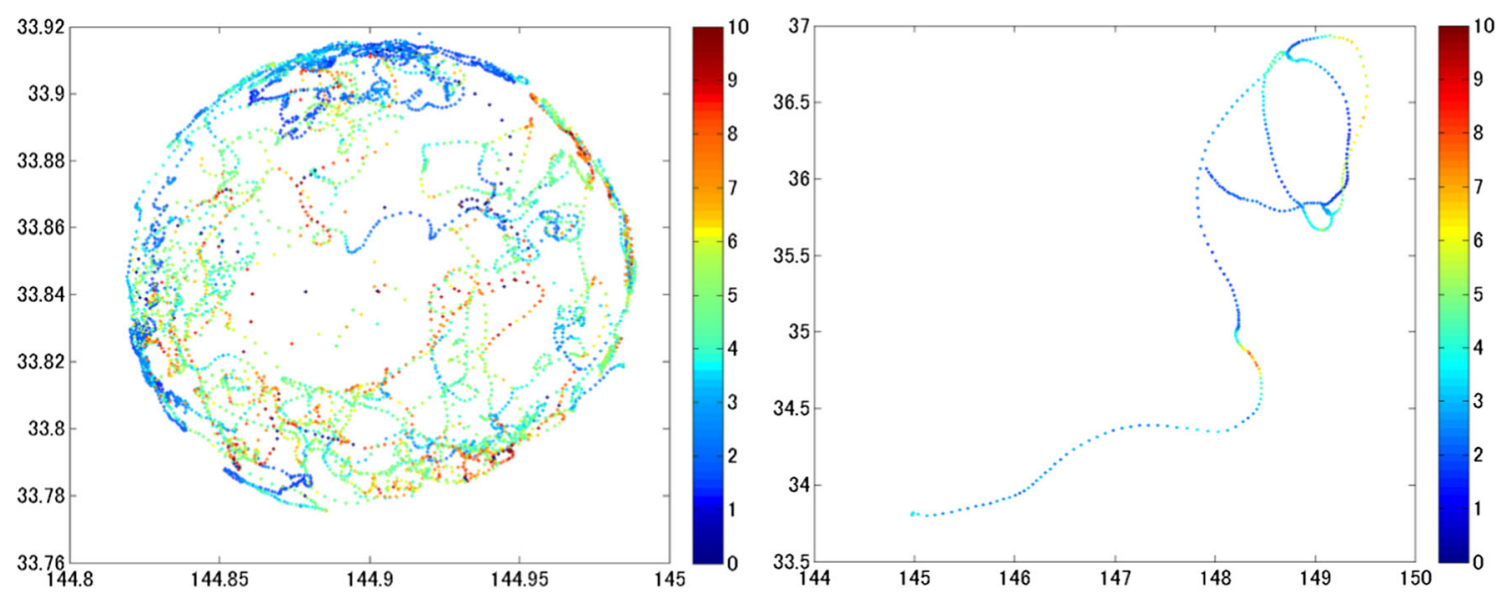

Fig. 8 NKEO buoy locations during June 20, 2012-March 8, 2013 (left) and during March 8-23, 2013 (right). The color represents maximum wave height for each 20-min record. The buoy locations are distributed in a circle of approximately $6,000 \mathrm{~m}$ radius, in the left figure 


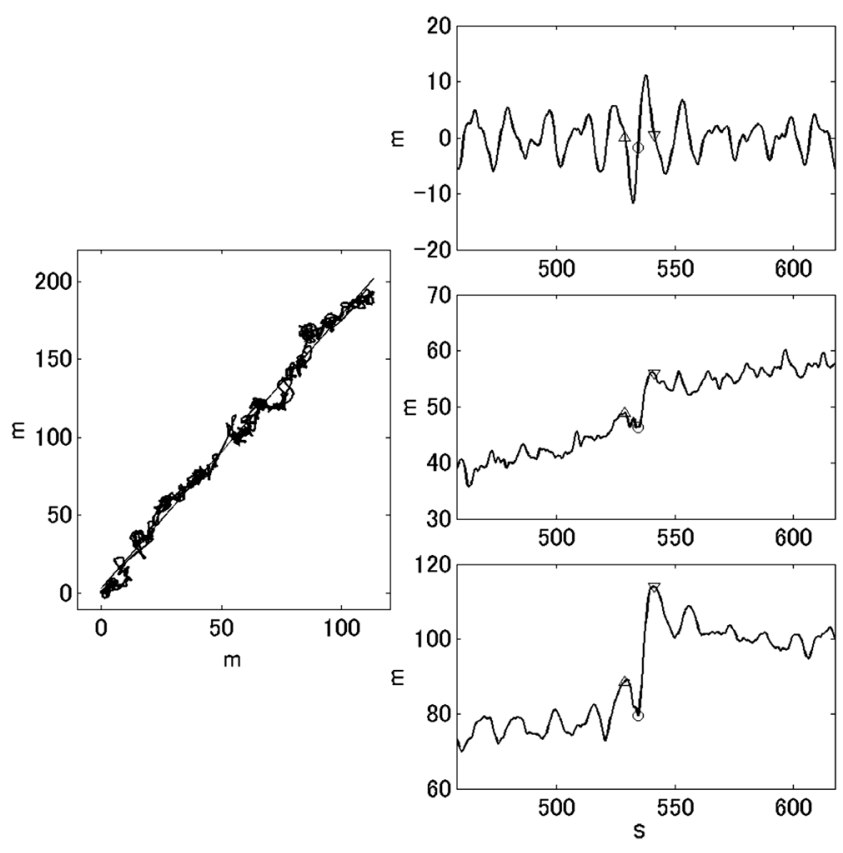

Fig. 9 Plane view of the 20-min trajectory of the K-TRITON buoy when the maximum wave height of $22.8 \mathrm{~m}$ was observed (October 4, 2012, 1 AM UTC; left). Time series of the filtered surface elevation (top right) and un-filtered zonal (middle right) and meridional (lower right) positions. Upper and lower triangles correspond to the zero-up crossing points indicating the individual wave with largest down-crossing wave height in record

linear orbital velocity (Tulin and Landrini 2001). The maximum horizontal velocities of the highest zero-up crossing and

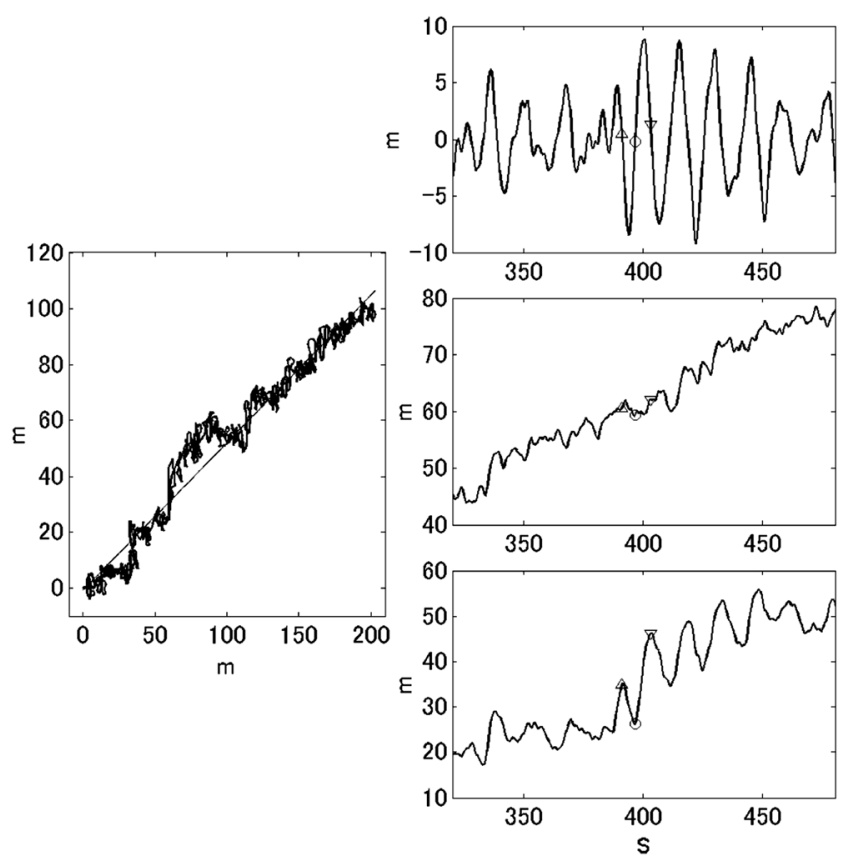

Fig. 10 Plane view of the 20-min trajectory of the K-TRITON buoy when the maximum wave height of $17.3 \mathrm{~m}$ was observed (October 4, 2012, 2 AM UTC; left). Time series of the filtered surface elevation (top right), and un-filtered zonal (middle right), and meridional (lower right) positions
JKEO NKEO Up/Down-crossing, KC40
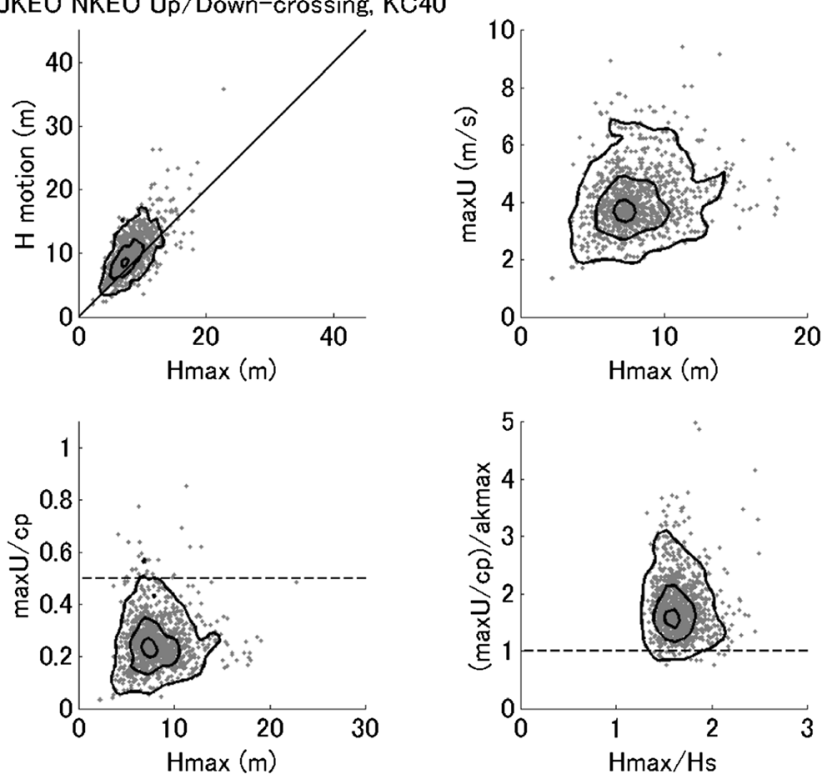

Fig. 11 The magnitude of the horizontal excursion of the buoy corresponding to the largest wave in each 20 -min record is plotted against maximum wave height $\left(H_{\max }\right)$ (upper left). The $U_{\max }$ (upper right) and the $U_{\max } / \mathrm{cp}$ (lower left) are plotted against $H_{\max }$; note that the drift speed of the buoy is subtracted from the horizontal speed. The ratio of the normalized maximum wave height and the wave steepness of the corresponding wave is plotted against $\mathrm{AI}$ (abnormality index $H_{\max } / H_{\mathrm{s}}$; lower right). The contour lines indicate exceedance probability of 10,50 , and $90 \%$

down-crossing waves in the 20-min records were analyzed (Fig. 11). Note that the data presented here are quality controlled by the KC number as described in Section 2, hence cases where the buoy did not follow the orbital motion of the wave are removed ${ }^{5}$. Because the horizontal excursion of the buoy tends to exceed the wave height (upper left), the horizontal speed must be higher than the weakly non-linear orbital speed $U=(a k) C_{p}$, where $a k$ is derived from individual wave height and period. The maximum horizontal speed was estimated from the buoy motion removing the slow translation speed due to current and wind (Fig. 11, upper right). The data does not show any indication of the wave height limiting the horizontal speed, hence assuring that the buoy motion is not constrained by the mooring cable. For each individual wave, the zero-crossing period is used to estimate the phase velocity. The maximum horizontal speed normalized by the phase speed $U / C_{p}$ is mostly below 0.4 , but was quite scattered and reached as high as 1 (Fig. 11, lower left). The $U / C_{p}$ equals the steepness $a k$, according to weakly non-linear theory. Hence the exceedance of $U / C_{p}$ to $a k$ represents the degree of nonlinearity of the wave. The ratio $U / C_{p} / a k$ ranges mostly below 3 but at times can reach almost 5 (Fig. 11, lower right). The peak

\footnotetext{
${ }^{5}$ For a typical laboratory particle tracking velocimetry, the $\mathrm{KC}$ number is over 100. The threshold value of $\mathrm{KC}$ number was set to 40 so as not to exclude too many data points for the analysis.
} 
JKEO NKEO untethered Up/Down-crossing, KC40
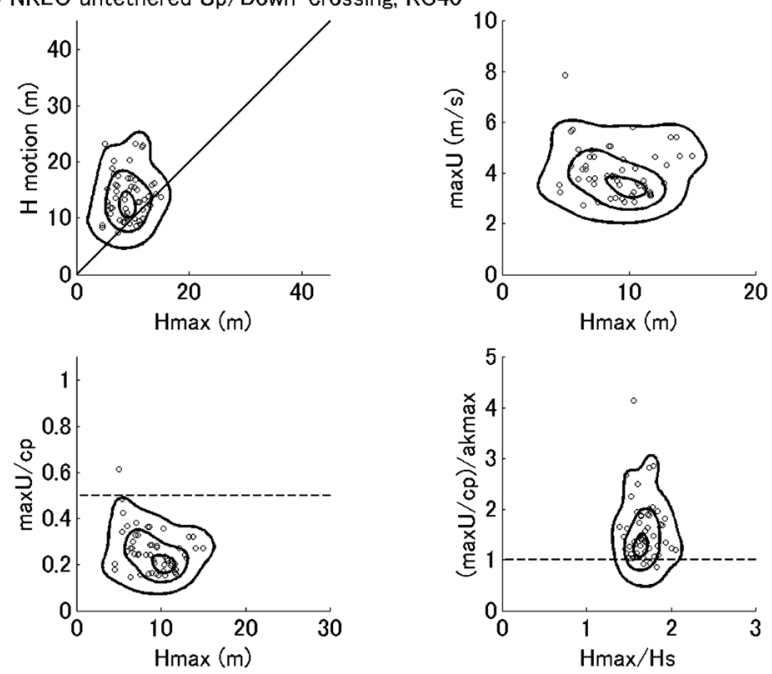

Fig. 12 The same as Fig. 8 but for an untethered buoy during March 8 23,2013

of the distribution is slightly over 1 and therefore considerable amount of waves are nonlinear but not necessarily breaking since $U / C_{p}$ is less than 0.5 . The average value of $U / C_{p} / a k$ was around 1.78 for the mean wave period of around $11 \mathrm{~s}$. The steepness of these extreme waves were in average around 0.147 , see Table 1 . Because the significant steepness was around 0.078 , occurrence probability of freak wave is considered to be normal. Thus, the current analysis indicates that the particle speed of extreme waves in a group, but not necessarily statistically rare, exceeds the weakly non-linear estimate of the orbital speed.

In order to validate the analysis of the horizontal speed observed by the K-TRITON buoy, the same analysis was conducted for the period when the buoy was untethered and freely drifting (March 8-23, 2013). Apparently, the horizontal excursion of the buoy was much larger than the wave height (Fig. 12, upper left). As can be seen from the buoy track after the mooring cable got cut loose (Fig. 8, right), the translation speed of the untethered buoy is larger. To eliminate the ambiguity of the speed estimate caused by this large horizontal

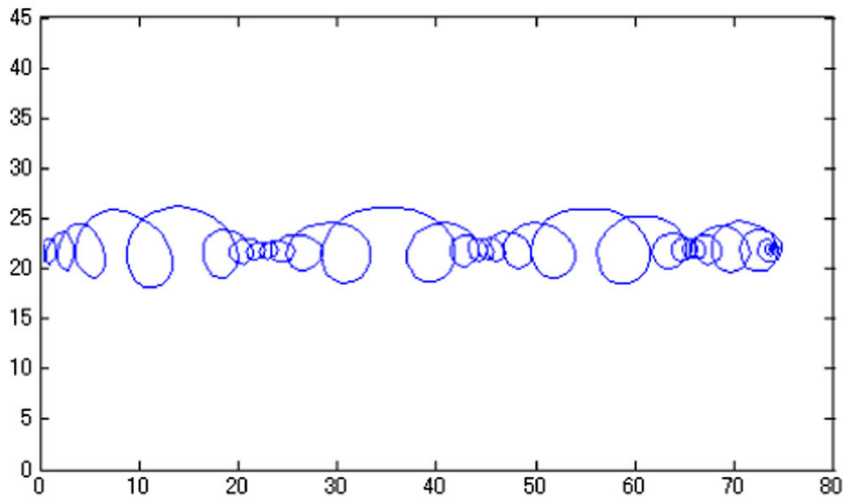

displacement, the translation speed due to buoy drift was subtracted. As a result, the distribution of the observed and normalized maximum horizontal velocity against maximum wave height (Fig. 12, upper right, lower left), and the relationship between the degree of nonlinearity $U / C_{p} / a k$ and the abnormality index $\mathrm{AI}=H_{\max } / H_{1 / 3}$ (Fig. 12, lower right), are consistent with the earlier analysis of data obtained when the buoy was moored. Since the number of data is significantly lower than the tethered case, the distribution at high values of $U / C_{p}$ is sparse.

The tethered and untethered buoy records gave us a unique opportunity to evaluate the influence of mooring cable to the motion of the buoy in Deep Ocean. The comparison showed that the buoy motion is not constrained by the mooring cable. Dynamic analysis of the mooring system is necessary to assure this conclusion. We have conducted a preliminary computation with a finite element model but it was difficult because of the elasticity of the cable and possible loss of cable tension which made the system numerically unstable. An alternative method, if cable curvature is small, is to use a lamped-mass mooring cable model which is more stable.

\section{Discussion}

When waves break, the speed of the particle at the crest accelerates to $U=O\left(C_{p}\right)$. As a result, the fluid particle orbit completely opens. Tulin and Landrini (2001) showed numerically that even if the waves are not breaking, the particle at the peak of a wave group accelerates. The fluid particle motion was visualized in a small wind-wave flume $(10.0 \mathrm{~m}$ long, $60 \mathrm{~cm}$ wide, and $80 \mathrm{~cm}$ deep) at the University of Tokyo, Kashiwa Campus by tracking a marker floating on the free surface (Takahashi 2012). The float is a 5.8-mm-diameter polystyrene sphere of specific gravity 0.98 . The images were taken 24 frames per second and the maker float was tracked digitally. The Stokes drift of a 1-m-long regular wave was estimated with an error of less than $1 \%$.

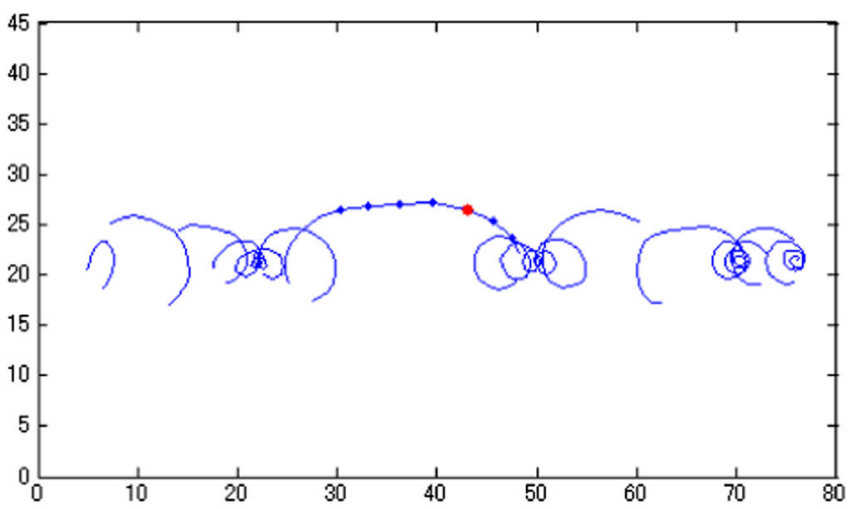

Fig. 13 A particle trajectory of modulated wave train for non-breaking $(l e f t)$ and breaking $($ right $)$ cases. The vertical and horizontal axes are length scale in centimeter 


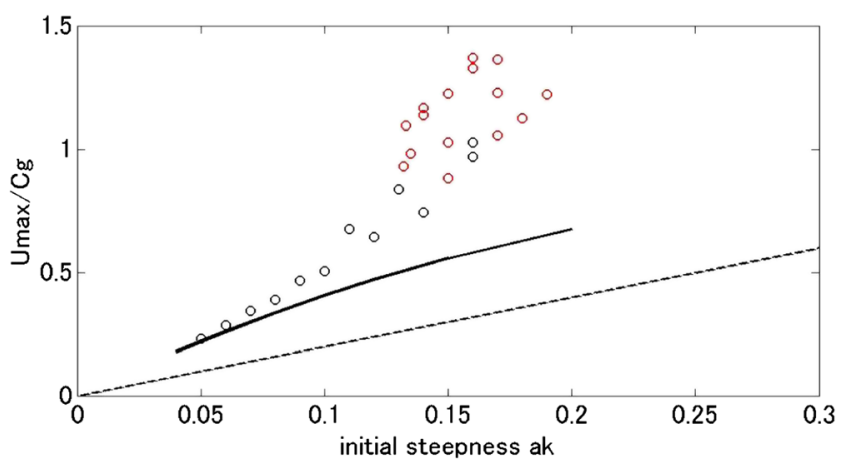

Fig. 14 The normalized maximum horizontal particle speed of the unidirectional modulated wave train is plotted against the initial steepness. The circles are the measured values from the tank experiment; $r$ red denotes breaking events. The broken line corresponds to $U=(\mathrm{ak}) C_{p}$ using the initial steepness; the solid line corresponds to $U=(\mathrm{ak})_{\mathrm{NLS}} C_{p}$ where the steepness is based on weakly nonlinear estimate of modified Nonlinear Shroedinger equation

By controlling the steepness, uni-directional non-breaking wave groups and breaking wave-groups of carrier wave wavelength $1 \mathrm{~m}$ were produced in the flume following the method outlined in Tulin and Waseda (1999). Even when the waves are not breaking, the particle repeatedly accelerates and the orbit completely opens (Fig. 13, left). Magnitude of the horizontal excursion of the particle is much larger when the waves are breaking (Fig. 13, right). The estimated horizontal speed of the particle of the non-breaking case was $46.4 \mathrm{~cm} / \mathrm{s}$
( $37 \%$ of phase speed) and of the breaking case was $82.8 \mathrm{~cm} / \mathrm{s}$ (66 \% of phase speed).

According to Tulin and Landrini (2001), the waves will inevitably undergo breaking when the particle speed exceeds the group velocity. To test this hypothesis, the measured particle speeds for all the cases $(\mathrm{ak}=0.05 \sim 0.2)$ are plotted against the initial wave steepness of the modulated wave trains (Fig. 14). As the initial steepness increases, the particle speed accelerates at the peak of the modulation, and when the speed exceeds the group velocity, the waves broke (red circles). The measured particle speed did not reach the phase speed but the particle speed is much larger than the speed estimated based on the weakly nonlinear theory (solid line); the local wave amplitude was obtained numerically by the modified Nonlinear Schroedinger equation (mNLS, Trulsen and Dysthe 1990). In other words, the particle speed is larger than the quasi-linear estimate using the maximum amplitude of the envelope ( $U$ observed $\left.>(A(x, t) k)_{\text {local }} C_{p}\right)$. The observed maximum wave amplitudes $a_{\max }$ reached about twice the initial wave amplitudes $a_{0}$ but were less than $(1+\sqrt{2}) a_{0}$ corresponding to the analytical solution of NLS (Akhmediev et al. 1987) (figure not shown). Therefore, the tank experiment indicates that the particle velocity can reach a much higher value than that estimated from the local wave amplitude.

Because the experiment was conducted following a single float, it was unlikely to have recorded the largest particle speeds which can approach the phase speed. Likewise, the
Fig. 15 The Response Amplitude Operators of the heave, surge, and pitch motion of the K-TRITON buoy. The pitching resonance frequency of various combinations of radius of gyration and longitudinal metacentric height is plotted in lower right figure
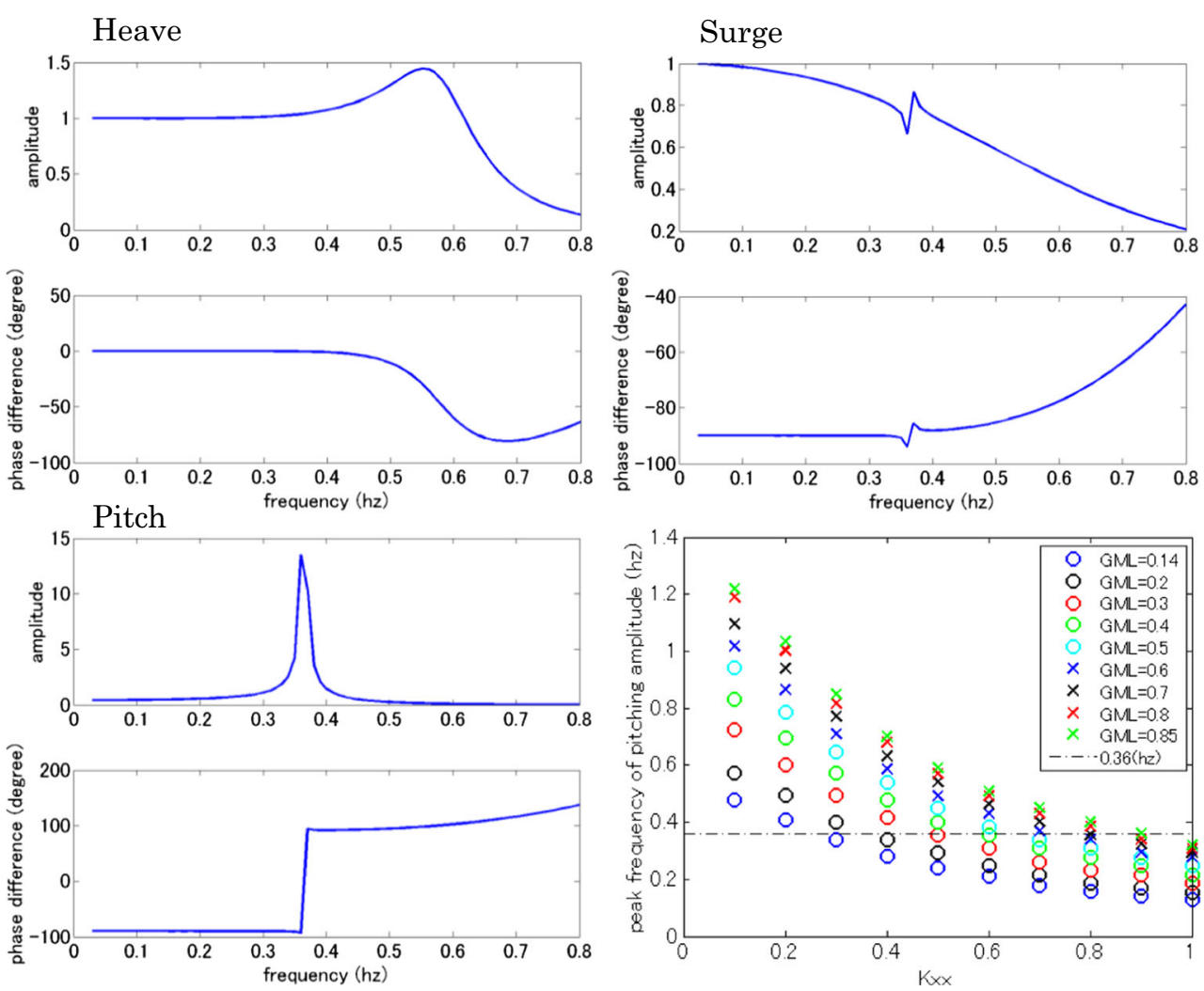

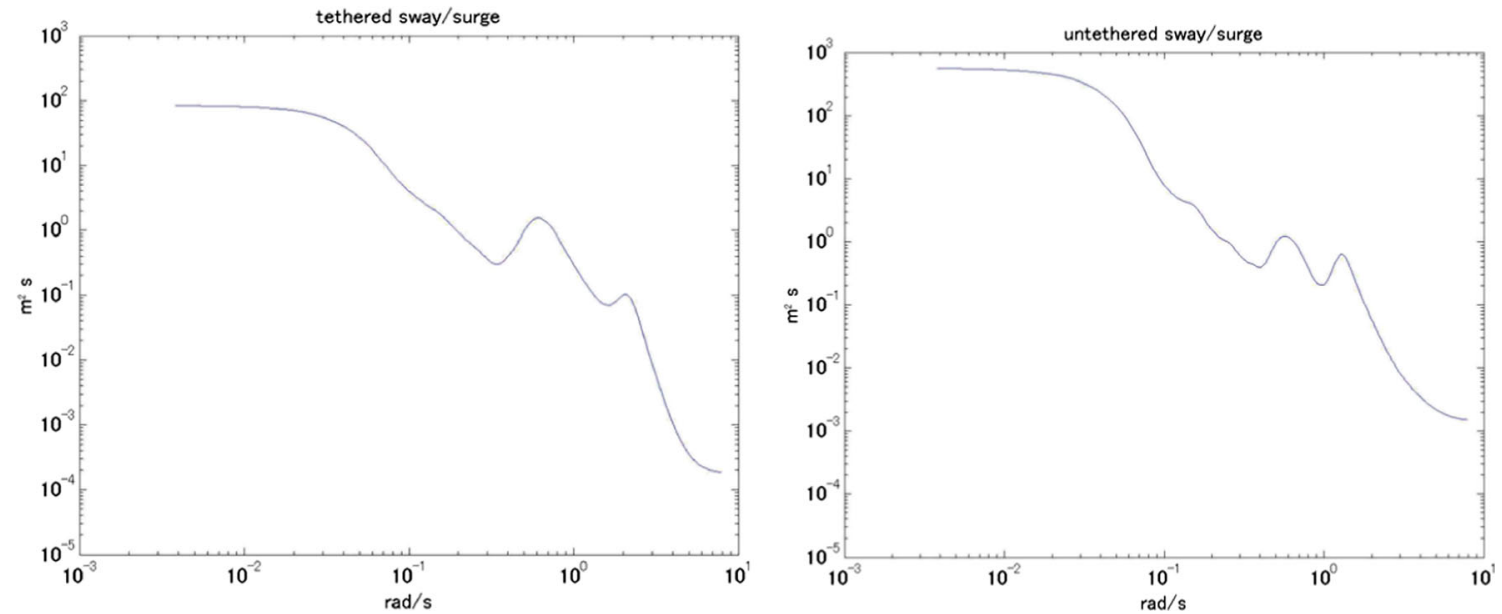

Fig. 16 The spectrum of the east-west motion; tethered (left) and untethered (right) cases from the NKEO observation

K-TRITON buoy would have likely missed observing the largest speed of the propagating waves. Nevertheless, the observed normalized horizontal speed of the buoy $U / C_{p}$ reached as high as 4 to 5 times the wave steepness $(\mathrm{ak})_{\text {local }}$ (Fig. 11, lower right), which corresponds to maximum horizontal speed around 60 to $80 \%$ of the phase speed. According to Tulin and Landrini (2001), waves whose particle velocity exceeded the group speed should undergo breaking. It is likely that the K-TRITON buoy had encountered a number of breaking waves. Whether the freak waves necessarily break or not is an open question. From our observations, a large population of data for the freak waves (e.g., $H_{\max } / H_{\mathrm{s}}>2$ ) are distributed around $U_{\max } / C_{p} /(\mathrm{ak})_{\max }=1.0-2.0$. Therefore, the observed freak waves were most likely not breaking.

\section{Conclusion}

A GPS sensor was attached to a slack-moored oceanographic/ meteorological buoy in the North West Pacific near Japan at a depth $5,000 \mathrm{~m}$. The buoy was not originally designed to measure ocean waves, but through data analysis and comparison with wave hindcast model, the buoy motion was proven to represent orbital motion of the ocean waves. In addition to the surface elevation, special attention was paid to the horizontal motion of the buoy. Conventional Eulerian observation by fixed sensors cannot measure the Lagrangian motion of the water particle. This study demonstrated the usefulness of Lagrangian wave observations based on GPS positioning of a moored, surface following buoy. By analyzing the highest waves in each 20-min records, we have shown that the fluid particle speed can accelerate at the peak of the wave group and far exceed the phase speed estimated by weakly nonlinear theory. The maximum wave height observed was $22 \mathrm{~m}$ and the associated horizontal speed was about $12 \mathrm{~m} / \mathrm{s}$. In the last few decades, freak waves have been studied extensively from a statistical point of view and the community seemed to have reached to a consensus on the significance of weak nonlinearity. However, what the sea farers care about is whether freak waves are dangerous "monster wave" or not. Whether such waves can be a threat to ships navigating in seas or offshore platforms wait for further research. This study demonstrated the usefulness of Lagrangian wave observation based on GPS positioning of tethered buoy.

Acknowledgements The first author acknowledges H. Tomita, A. Nagano, and K. Taniguchi of JAMSTEC for their assistance in conducting the K-TRITON buoy observation. He also acknowledges S. Komori and H. Yoshida of Zeni Lite Buoy Co. for their assistance in setting up the GPS wave sensor. The research was supported by Grant-in-Aid for Scientific Research. WAFO (2000) was used in the analysis.

\section{Appendix 1: K-TRITON buoy and its response amplitude operator}

The K-TRITON buoy was developed based on the m-Triton system which is a low-cost lightweight buoy system developed for use in the Indian Ocean (Ishihara et al. 2010). The slack-mooring system (Fig. 2) was composed of three segments: a polypropylene rope with positive buoyancy in the lower part, a nylon rope with negative buoyancy in the upper part, and a wire rope segment directly beneath the buoy. The cable forms an S shape without external horizontal force. The particulars of the K-TRITON buoy and the overview of the JKEO site observations are summarized in:

http://www.jamstec.go.jp/iorgc/ocorp/ktsfg/data/jkeo/ index.html.

Ideally, the RAOs of each platform should be used to translate buoy motion to the wave signal. However, quite often the RAOs are not known, especially when the observational buoy is moored. Unlike discus buoys that measure the roll-pitch motion of buoy, GPS wave buoy measures the displacements directly. Therefore, the possible constraint of the horizontal motion by mooring cable is a concern. 
The heave, pitch, and surge RAOs of the buoy were estimated using a conventional three-dimensional boundary element method and are shown in Fig. 15. In the range of frequencies of our interest $(0.03-0.3 \mathrm{~Hz})$, the gain of the heave is nearly equal to 1 and the phase difference is null. The pitch and surge motions are $90^{\circ}$ out of phase, and their gain increase gradually with frequency. Pitch resonance frequency is around $0.36 \mathrm{~Hz}$. Because the distribution of weight is not known exactly, to compute the RAOs, the radius of gyration $K_{\mathrm{XX}}$ and longitudinal metacentric height GML were adjusted; Fig. 15, lower right. From the possible combinations of GML and $K_{\mathrm{XX}}$ that produce the observed pitch resonance frequency of $0.36 \mathrm{~Hz}, \mathrm{GML}=0.5 K_{\mathrm{XX}}=0.65$ were chosen.

When the buoy at the New KEO site (NKEO) was untethered because of cut mooring cable by accident from March 8 to 24, 2013, the resonant peak appeared at a much lower frequency and larger amplitude (Fig. 16). Our comparison of tethered and untethered buoy motion proves that the empirical adjustment of the radius of gyration effectively took care of the additional tension and damping effect of the mooring cable.

Open Access This article is distributed under the terms of the Creative Commons Attribution License which permits any use, distribution, and reproduction in any medium, provided the original author(s) and the source are credited.

\section{References}

Akhmediev NN, Eleonskii VM, Kulagin NE (1987) Exact first-order solutions of the nonlinear Schrödinger equation. Theor Math Phys 72(2):809-818

Cartwright DE, Longuet-Higgins MS (1956) The statistical distribution of the maxima of a random function. Proc Roy Soc London Series A 237:212-232

Collins CO III, Lund B, Waseda T, Graber HC (2014) On recording sea surface elevation with accelerometer buoys: lessons from ITOP (2010). Ocean Dyn 64(6):895-904

Dee DP, Uppala SM, Simmons AJ, Berrisford P, Poli P, Kobayashi S, ..., Vitart F (2011) The ERA Interim reanalysis: configuration and performance of the data assimilation system. Q J R Meteorol Soc 137(656), 553-597

Donelan M, Longuet-Higgins MS, Turner JS (1972) Periodicity in whitecaps. Nature 239:449-451

Haver S (2004) A possible freak wave event measured at the Draupner jacket January 1 1995. Proc. Rogue Waves 2004

Ishihara Y, Yamaguchi M, Fukuda T, Matsunaga H, Murashima T (2010) $\mathrm{m}$-TRITON and TRITON buoy system, Tropical Moored Buoy Implementation Panel-10, Scotland, 26 September, http://www. pmel.noaa.gov/tao/proj_over/tip/tip10_presentations.html

Kuroda Y, Amitani Y (2001) TRITON: new ocean and atmosphere observing buoy network for monitoring ENSO. Umi no Kenkyu 10:157-172 (in Japanese with English abstract)

Liu PC, Chen HS, Doong DJ, Kao CC, Hsu YJG (2008) Monstrous ocean waves during typhoon Krosa. Ann Geophys 26:1327-1329

Magnusson AK, MET-Norway B, Meteorology M (2013) Variability of sea state measurements and sensor dependence, Workshop:
Statistical models of the Metocean environment for engineering uses, IFREMER 30.09-01.10.2013

McPhaden M, Busalacchi AJ, Anderson DLT (2010) A TOGA Retrospective. Oceanography 23(3):86-103. doi:10.5670/oceanog. 2010.26

Meindl EA, Hamilton GD (1992) Programs of the National Data Buoy Center. Bull Am Meteorol Soc 73(7):985-993

Mizuta R, Oouchi K, Yoshimura H, Noda A, Katayama K, Yukimoto S, ..., Nakagawa M (2006) 20-km-mesh global climate simulations using JMA-GSM model-mean climate states. Journal of the Meteorological Society of Japan, vol 84(1), 165-185

Nagai T, Satomi S, Terada Y, Kato T, Nukada K, Kudaka M (2005, June) GPS buoy and seabed installed wave gauge application to offshore tsunami observation. In Proceedings of the Fifteenth International Offshore and Polar Engineering Conference (pp 292-299)

NCEP Office Note 442 (2003) The GFS Atmospheric Model, 14., www. weather.gov/ost/climate/STIP/AGFS_DOC_1103.pdf

Saha S, Moorthi S, Pan HL, Wu X, Wang J, Nadiga S, ..., Reynolds RW (2010) The NCEP climate forecast system reanalysis. Bulletin of the American Meteorological Society, 91(8), 1015-1057

Sinchi M (2011) Data analysis of the ocean wave observation for solving the generation mechanism of freak wave, Master's thesis, the University of Tokyo, Graduate School of Frontier Sciences (in Japanese)

Swail V, Jensen R, Lee B, Turton J, Thomas J, Gulev S, Yelland M, Etala P, Meldrum D, Birkemeier W, Burnett W, Warren G (2010) Wave measurements, needs and developments for the next decade. Proceedings of the OceanObs, ' 09

Takahashi S, (2012) Particle motions of nonlinear water waves, Master's thesis, the University of Tokyo, Graduate School of Frontier Sciences (in Japanese)

Tauchi T, Kohno N, Kimura M (2007) The improvement of JMA operational wave models, ftp://ftp.wmo.int/Documents/PublicWeb/amp/ mmop/documents/JCOMM-TR/J-TR-44/WWW/Papers/Full WaveW2007Tauchi.pdf

Toba Y (1973) Local balance in the air-sea boundary processes. J Oceanographical Soc Japan 29(5):209-220

Tomita H, Kubota M, Cronin MF, Iwasaki S, Konda M, Ichikawa H (2010) An assessment of surface heat fluxes from J-OFURO2 at the KEO and JKEO sites, J Geophys Res -Oceans 115:C03018, 10. 1029/2009jc005545.

Trulsen K, Dysthe KB (1990) Frequency down-shift through self modulation and breaking. In Water Wave Kinematics (pp 561-572). Springer Netherlands

Tulin MP, Landrini M (2001) Breaking waves in the ocean and around ships. In Twenty-Third Symposium on Naval Hydrodynamics

Tulin MP, Waseda T (1999) Laboratory observations of wave group evolution, including breaking effects. J Fluid Mech 378:197-232

WAFO-group (2000) "WAFO-A Matlab Toolbox for Analysis of Random Waves and Loads-A Tutorial" Math. Stat., Center for Math. Sci., Lund Univ., Lund, Sweden. ISBN XXXX, URL http:// www.maths.lth.se/matstat/wafo

Waseda T, Sinchi M, Nishida T, Tamura H, Miyazawa Y, Kawai Y, Ichikawa H, Tomita H, Nagano A, Taniguchi K (2011a) GPSbased wave observation using a moored oceanographic buoy in the deep ocean, Proceedings, June, ISOPE-Maui

Waseda T, Hallerstig M, Ozaki K, Tomita H (2011b) Enhanced freak wave occurrence with narrow directional spectrum in the North Sea. Geophys Res Lett 38, L13605. doi:10.1029/2011GL047779

Waseda T, Asaumi S, Kiyomatsu K (2014) Improving resource assessment of wave power based on spectral wave model, OMAE 2014, June 9-13, San Francisco, USA

Yamaguchi I, Kasai T, Igawa H, Harigae M, Komori S, Shigenaga T, Hosaka Y (2005) Ocean wave sensing system using pointpositioning GPS receiver, Space Engineering Conference, 14, 29 $34,2005-12-15$ 